Short Communication

\title{
PCB-77 disturbs iron homeostasis through regulating hepcidin gene expression
}

\author{
Lei Wang ${ }^{\text {a }}$, Shuping Zhang ${ }^{\mathrm{a}}$, Ronghai Lin ${ }^{\mathrm{b}}$, Long Li ${ }^{\mathrm{a}}$, Daoqiang Zhang ${ }^{\mathrm{b}}$, Xinghong Li $^{\mathrm{a}}$, Sijin Liu ${ }^{\mathrm{a}, *}$ \\ a State Key Laboratory of Environmental Chemistry and Ecotoxicology, Research Center for Eco-Environmental Sciences, Chinese Academy of Sciences, Beijing 100085, PR China \\ ${ }^{\mathrm{b}}$ Weifang Medical College, Wendeng Central Hospital, Weihai 264400, PR China
}

\section{A R T I C L E I N F O}

\section{Article history:}

Accepted 5 September 2013

Available online 19 September 2013

\section{Keywords:}

PCB-77

Hepatocytes

Hepcidin

Iron homeostasis

\begin{abstract}
A B S T R A C T
PCBs are a family of persistent environmental toxicants with a wide spectrum of toxic features, such as immunotoxicity, hepatoxicity, endocrine disruption effects, and oncogenic effects. To date, little has been done to investigate the potential influence of PCB exposure on iron metabolism. Deregulated iron would lead to either iron deficiency or iron excess, coupled with various diseases such as anemia or hemochromatosis. Iron metabolism is strictly governed by the hepcidin-ferroportin axis, and hepcidin is the key regulator that is secreted by hepatocytes. Here, we found that PCB-77 could go through plasma membrane and accumulate in hepatocytes. PCB-77 was demonstrated to suppress hepcidin expression in HepG2 and L-02 hepatocytes. Moreover, hepatic hepcidin was observed to be inhibited in mice upon administration of PCB-77. Due to reduced hepcidin concentration, serum iron content was increased, with a significant reduction of splenic iron content. Together, we deciphered the molecular mechanism responsible for PCB-conducted disturbance on iron homeostasis, i.e. through misregulating hepatic hepcidin expression.
\end{abstract}

(C) 2013 Elsevier B.V. All rights reserved.

\section{Introduction}

Polychlorinated biphenyls (PCBs) with 209 congeners, according to the position of the chlorine atoms in the biphenyl ring, are a class of lipophilic inert compounds. PCBs, originally manufactured commercially for industrial applications, were appreciated for their insulating and flame resistant properties (Safe, 1994); however, commercial productions were banned in the United States in 1979. PCBs, with slow rates of biotransformation in our biosphere, cause a variety of adverse effects on human health including reproductive, neurological and endocrine disorders (Loch-Caruso, 2002; Portigal et al., 2002; Schantz et al., 2003). Although a number of studies have investigated the toxicities of PCBs from various aspects, such as reproductive toxicity (Richthoff et al., 2003), inhibition of growth (COLE and PLAPP, 1974), immunotoxicity (Smialowicz et al., 1989; Tryphonas, 1995), hepatoxicity (Yoshimura et al., 1979), endocrine disruption effects (Birnbaum, 1994), neurotoxicity (Kodavanti and Tilson, 1996), enzyme induction (Burgin et al., 2001), and oncogenic effects (Lucena et al., 2001; Wolff et al., 2000; Zheng et al., 2000), the molecular mechanisms underlying these adverse effects are still elusive. Moreover, the potential influence of PCBs on iron metabolism has not been studied thus far.

Abbreviations: BMP, bone morphogenetic protein; DMSO, dimethylsulfoxide; ERE, estrogen response elements; GC-MS, gas chromatography-mass spectrometry; IL-6, interleukin- 6; LDH, lactate dehydrogenase; MTT, 3-(4,5-dimethylthiazol-2-yl)-2,5-diphenyltetrazolium bromide; PCB-77, 3,3',4,4'-tetrachlorobiphenyl; PCBs, polychlorinated biphenyls; qRT-PCR, quantitative real-time polymerase chain reaction.

* Corresponding author.

E-mail address: sjliu@rcees.ac.cn (S. Liu).
Iron is an essential constituent of the internal environment and an absolute element for nearly all forms of life. Iron participates in multiple biological processes, e.g. DNA synthesis (Ganeshaguru et al., 1980) and protein formation (Duce et al., 2010). It is crucial to maintain iron homeostasis; otherwise both iron overload and iron deficiency result in toxicities through promoting oxidative stress (Knutson et al., 2000). A tight control of the balance for iron intake, utilization and storage is therefore fundamentally important for cells to keep cells healthy. Hepcidin, a 25-amino-acid peptide secreted by the liver, is the central regulator of systemic iron homeostasis (Elizabeta Nemeth et al., 2004). It binds to ferroportin, the major iron exporter in mammals, and causes internalization of ferroportin, leading to iron retention inside cells (Ganz and Nemeth, 2011). Hepcidin primarily inhibits intestinal iron absorption by blocking ferroportin-conducted iron transportation from the gastrointestinal system to the circulating system (Evstatiev and Gasche, 2012). It also prevents iron release from ferroportin-expressing cells, such as macrophages and hepatocytes, resulting in iron accumulation in local tissues (Bekri et al., 2006). Hepcidin expression is fundamentally governed by the BMP family members (Andriopoulos et al., 2009) and the IL-6 family cytokines (Banzet et al., 2012) through erythropoietic demand, iron burden and inflammatory stimuli (Ganz, 2010). Hepcidin deficiency is associated with increased serum iron and leads to a few iron-related disorders, such as nervous system diseases (Jeong and David, 2003), hepatocirrhosis (Fei et al., 2006) and even cancers (Bystrom et al., 2012; Nemeth and Ganz, 2006).

The aim of this study was to evaluate the potential effects of PCBs on iron homeostasis. Here, we found that PCB-77, a representative $\mathrm{PCB}$ congener that is widely spread in the environment, could 
significantly alter systemic iron homeostasis through misregulating hepatic hepcidin.

\section{Materials and methods}

\subsection{Chemicals and reagents}

PCB-77 (3,3',4,4'-tetrachlorobiphenyl) was purchased from the AccuStandard Inc. Dimethyl sulfoxide (DMSO) (Solarbio Inc., China) was used to dissolve PCB-77. The final concentration of DMSO in culture medium was $<0.1 \%$.

\subsection{Cell culture}

Human hepatic carcinoma cell line HepG2 and hepatic epithelial cell line L-02 were obtained from the Shanghai Cell Bank of Type Culture Collection of the Chinese Academy of Sciences. Cells were cultured in RPMI 1640 medium (Gibco) supplemented with 10\% fetal bovine serum (FBS, Hyclone) and $100 \mathrm{U} / \mathrm{mL}$ penicillin-streptomycin (Hyclone) at $37{ }^{\circ} \mathrm{C}$ under $5 \% \mathrm{CO}_{2}$.

\subsection{Cytotoxicity assays}

Cytotoxicity was assessed by the MTT assay following the instructions from the manufacturer (Roche). Briefly, cells were serum starved for $12 \mathrm{~h}$ and were then inoculated into 96-well plates at a concentration of $6.0 \times 10^{3}$ cells/well upon different treatments. Cells were cultured for another $24 \mathrm{~h}$, and $20 \mu \mathrm{L}$ MTT ( $5 \mathrm{mg} / \mathrm{mL}$ ) was added into each well followed by incubation for $4 \mathrm{~h}$. Thereafter, $200 \mu \mathrm{L}$ DMSO was added into each well, and 96-well plates were read at $490 \mathrm{~nm}$ on a microplate reader (Thermo) after shaking. Lactate dehydrogenase (LDH) release into culture media after exposure to PCB-77 was detected with a kit of CytoTox-ONETM Homogeneous Membrane Integrity Assay according to the manufactures' instructions (Promega).

\subsection{Gas chromatography-mass spectrometry (GC-MS)}

Quantification of PCB-77 was performed using an Agilent 6890 GC, coupled with 5973 MSD. The MS analyses were conducted in an electron capture negative ionization (ECNI) mode, and separation was performed using a fused silica capillary column (RTX-1614, $30 \mathrm{~m}$, $0.25 \mathrm{~mm}$ ID and $0.1 \mu \mathrm{m}$ film thickness). The carrier gas used was helium, with a flow rate of $1.0 \mathrm{~mL} \mathrm{~min}^{-1}$, and methane was used as the reaction gas. The GC oven temperature was programmed as follows. The initial temperature was $120^{\circ} \mathrm{C}$ maintained for $1 \mathrm{~min}$, and was then increased to $150{ }^{\circ} \mathrm{C}$ at a rate of $30{ }^{\circ} \mathrm{C} \mathrm{min}{ }^{-1}$, followed by a $2.5^{\circ} \mathrm{C} \mathrm{min}-1$ ascent to $280^{\circ} \mathrm{C}$. The temperatures for the injector, the transfer line and the ion source were $290{ }^{\circ} \mathrm{C}, 280{ }^{\circ} \mathrm{C}$, and $230{ }^{\circ} \mathrm{C}$, respectively.

\subsection{Animal experiments}

All animal care and surgical procedures were approved by the Animal Ethics Committee at the Research Center for Eco-Environmental Sciences, Chinese Academy of Sciences. Female Balb/c mice of six weeks old were purchased from the Vital River Laboratories, China, and housed under a sterile and pathogen-free environment. Mice in the treatment group received a single dose of intraperitoneal (i.p.) injection of PCB-77 diluted in corn oil ( $80 \mathrm{mg} / \mathrm{kg})$. The control mice received coil only. The iron content in diet was $480 \mathrm{mg} / \mathrm{kg}$ in the current study.

\subsection{RNA extraction and $q R T-P C R$ analysis}

Total RNAs were isolated from cells using Trizol according to the manufacturer's instructions (Invitrogen). Tissue samples were first pulverized in liquid nitrogen and then total RNAs were extracted with TriPure following the instruction provided by the manufacturer
(Roche). Quantitative measurements of gene expression were carried out with SYBR Green qPCR master mix (Qiagen) on qPCR Systems Mx3005P (Stratagene). Primer sequences for PCR reactions were as follows, mouse hepcidin: forward, 5'-CTGAGCAGCACCACCTATCTC- $3{ }^{\prime}$, and reverse, 5'-TGGCTCTAGGCTATGTTTTGC-3'; mouse HPRT: forward, 5'GCTTGCTGGTGAAAAGGACCTCTCGAAG-3', and reverse, 5'-CCCTGAAGT ACTCATTATAGTCAAGGGCAT-3'; human hepcidin: forward, 5'-CCTGACC AGTGGCTCTGTTT-3', and reverse, 5'-CACATCCCACACTTTGATCG-3'; human GAPDH: forward, 5'-GAAGGTGAAGGTCGGAGT-3', and reverse, 5'-GAAGATGGTGATGGGATTTC-3'. HPRT and GAPDH were used as an internal control for human or mouse samples, respectively.

\subsection{Determination of iron content}

Serum iron content was determined with a kit following the manufacturer's instructions (Nanjing Jiancheng Bioengineering Institute, China). Tissue non-heme iron was assayed following a standard protocol as previously described (Liu et al., 2007).

\subsection{Statistical analysis}

Independent $t$ test or one-way ANOVA test was used to analyze experimental data. Data were shown in mean \pm SE. $P<0.05$ were considered statistically significant.

\section{Results and discussion}

Liver is the preferential organ for PCB accumulation due to their significant characteristic of lipophilicity (Kodavanti et al., 1998). Meanwhile, liver is also the primary organ in governing iron homeostasis, and hepatocytes are the predominant cell type for hepcidin synthesis which is the central hormone in regulating iron uptake, distribution and storage (Drakesmith and Prentice, 2012; Ganz, 2010). To accurately uncover the potential effects of PCBs on iron metabolism, we first attempted to choose sublethal concentrations of PCB-77 in cell treatment by avoiding significant toxicity to hepatocytes. As shown in Fig. 1A, the MTT assay revealed that there was no significant cytotoxicity of PCB-77 to HepG2 cells within the concentration range from $0.01 \mu \mathrm{M}$ to $2 \mu \mathrm{M}$. Membrane integrity could be assessed by the release of a cytosolic enzyme, LDH, into culture medium (Hawkins and Abrahamse, 2006). We thus evaluated the loss of membrane integrity of HepG2 cells upon treatment with PCB-77. The LDH release assay indicted that PCB-77 at the current concentrations had no effect on the extracellular LDH concentrations (Fig. 1B), in agreement with the results from the MTT assay (Fig. 1A).

The biological effects of environmental pollutants closely rely on their bioavailability by cells (Serrano et al., 2009). Bioavailability is the fraction that reaches into cells of the total amount administered. In the present study, we measured the bioavailability of PCB-77 by HepG2 cells. Based on the viability assays as shown in Fig. 1, a nontoxic concentration of $0.1 \mu \mathrm{M}$ was chosen to assess the uptake of PCB-77 by HepG2 cells. The uptake of PCB-77 was analyzed with the approach of GC-MS. PCB-77 treatment in culture medium at $0.1 \mu \mathrm{M}$ (equivalent to $59.6 \mathrm{ng}$ for all cells in the culture well) for $24 \mathrm{~h}$ resulted in accumulation of $2.26 \mathrm{ng}$ PCB-77 in $1.0 \times 10^{6} \mathrm{HepG} 2$ cells (Fig. 1C). Therefore, the amount of PCB-77 that entered $1.0 \times 10^{6}$ cells accounted for $3.8 \%$ of the total amount in the culture medium (Fig. 1C). These results demonstrated that PCB-77 could readily enter cells without damaging cells.

We thereafter assay the possible influence of PCB-77 treatment on hepcidin expression. As shown in Fig. 2A, the mRNA level of hepcidin in HepG2 cells was significantly inhibited by more than $50 \%$ at $0.1 \mu \mathrm{M}$ for $24 \mathrm{~h}(P=0.001)$. To substantiate this finding, we examined hepcidin expression in another hepatocyte cell line L-02. Hepcidin expression was significantly repressed by $59 \%$ in L-02 cells with $\mathrm{PCB}=$ 77 treatment at $0.1 \mu \mathrm{M}$ for $24 \mathrm{~h}$ (Fig. $2 \mathrm{~B}, P<0.05$ ), similar to the finding in HepG2 cells. Dysregulation of hepcidin production results in a variety 
A)

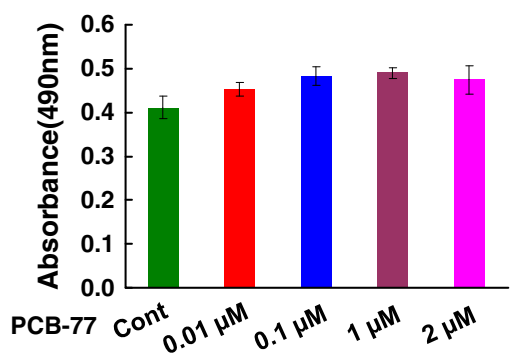

B)

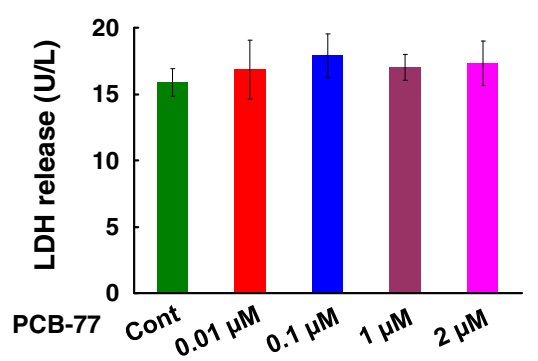

\begin{tabular}{rcc} 
C) & & \\
\hline $\begin{array}{c}\text { Amount of PCB-77 exposed } \\
\text { to HepG2 cells }\end{array}$ & $\begin{array}{c}\text { Absorption of PCB-77 } \\
\text { in every } 10^{6} \text { cells }\end{array}$ & $\begin{array}{c}\text { Absorption rate of PCB-77 } \\
\text { in every } 10^{6} \text { cells }\end{array}$ \\
\hline $59.6 \mathrm{ng}(0.1 \mu \mathrm{M})$ & $2.26 \pm 0.51 \mathrm{ng}$ & $3.8 \pm \mathbf{0 . 8 5 \%}$ \\
\hline
\end{tabular}

Levels of PCB-77 in control group are below the limit of detection

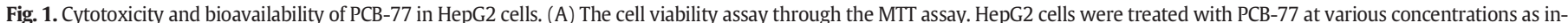

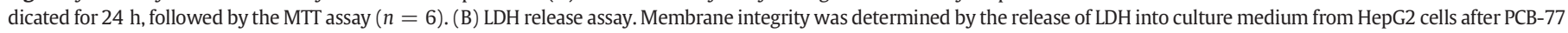

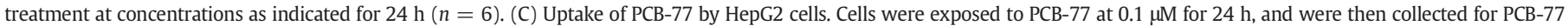
quantification with GC-MS $(n=6)$.

of iron disorders. For example, hepcidin deficiency leads to the development of systemic iron overload due to excessive iron absorption and iron release from macrophages, as hepcidin knock-out mice displayed severe iron overload (Nicolas et al., 2001). Hepcidin deficiency is coupled to a few iron diseases, such as hemochromatosis and $\beta$-thalassemia (Pietrangelo, 2011).

To confirm the inhibitory effect of PCB-77 on hepcidin expression, we looked into hepcidin expression in mice upon PCB-77 administration. We performed animal experiments with short-term administration for 6 h, 12 h, 24 h, 2 days and long-term administration for 10 days. Mice were i.p. injected with PCB-77 and were then sacrificed after $6 \mathrm{~h}$, 12 h, 24 h, 2 days or 10 days. Regarding the short-term administration of PCB-77, the qRT-PCR results showed that hepatic hepcidin expression was consistently suppressed more than $65 \%$ at $6 \mathrm{~h}, 12 \mathrm{~h}$ and $24 \mathrm{~h}$ after PCB-77 administration, compared to that in the mice without PCB administration (Fig. 3A, $P<0.05$ ). There was no significant alteration to the body iron status in the PCB-77 administrated mice, as the concentrations of serum iron, hepatic iron and splenic iron were not significantly changed with a slight increase in serum iron and a slight decrease in splenic iron at $24 \mathrm{~h}$ (Fig. 3B-D, $P>0.05$ ), suggesting a slow adjustment in serum and spleen iron in response to hepcidin changes. However, there were significant alterations in the body iron status 2 days after PCB-77 administration in mice. The hepcidin level was reduced by $45 \%$
A)

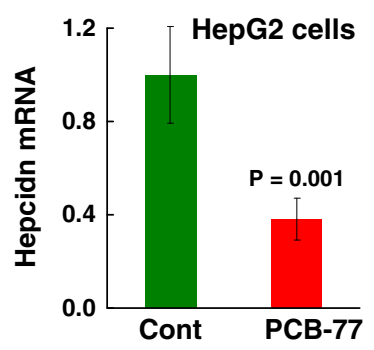

B)

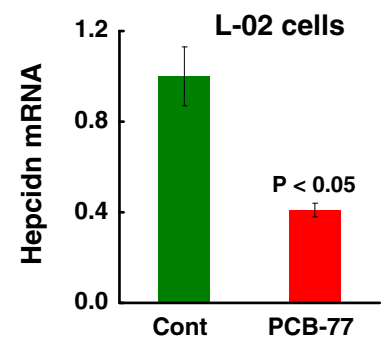

Fig. 2. Inhibition of hepcidin mRNA expression in vitro by PCB-77. HepG2 cells (A) and L-02 cells (B) were treated with $0.1 \mu \mathrm{M}$ PCB-77 for $24 \mathrm{~h}$, and hepcidin mRNA levels were measured by qRT-PCR $(n=4)$.
2 days after PCB-77 administration, compared to that in the control mice (Fig. 4A, $P<0.05$ ). Subject to the reduction of hepatic hepcidin for 2 days, serum iron was elevated by more than 2.3 fold in mice treated with $\mathrm{PCB}-77$, compared to the untreated mice (Fig. $4 \mathrm{~B}, P<0.05$ ). Meanwhile, the splenic iron was decreased by approximately $40 \%$ in mice administrated with $\mathrm{PCB}-77$, compared to the control mice (Fig. 4C, $P<0.05$ ). The liver iron concentration kept consistent with or without PCB-77 administration (Fig. 4D, $P>0.05$ ).

With respect to the long-term administration of $\mathrm{PCB}-77$ for 10 days, the hepcidin expression was consistently repressed by approximately $65 \%$, and the serum iron concentration was increased by $60 \%$, compared to the control mice (Figs. $4 \mathrm{E}$ and $\mathrm{F}, P<0.05$ ). However, spleen iron content was similar between the $\mathrm{PCB}-77$-treated mice and the control mice for 10 days (Fig. $4 \mathrm{G}, P>0.05$ ). Liver iron content did not significantly change (Fig. $4 \mathrm{H}, P>0.05$ ), similar to that in mice upon acute PCB-77 treatment (Figs. 3-4). The repletion of iron in spleen after chronic PCB77 treatment is presumably due to consecutive high-level iron absorption from small intestine subject to continuous hepcidin attenuation, leading to sufficient iron supply for various organs including spleen. Additionally, phagocytosis of senescent erythrocytes by macrophages in spleen could partially replenish lapsed iron during the long-term exposure.

Iron is an essential element necessary for numerous biological processes. For example, iron-containing proteins exert a variety of functions including gas transport, electron transfer in the respiratory chain, catalysts of biodegeneration or biosynthesis, transcription factors and repressors, enzymes of intermediate metabolism, and DNA synthesis and repair (Evstatiev and Gasche, 2012). However, deregulated iron homeostasis is involved in the development of diverse diseases including cancers (Bystrom et al., 2012) and neurodegenerative brain disorders (Benarroch, 2009). Liver-derived hormone, hepcidin, centrally modulates iron homeostasis by inducing the internalization and degradation of ferroportin, the only known cellular iron exporter that is expressed by duodenal enterocytes, macrophages and hepatocytes (Elizabeta Nemeth et al., 2004). Liver is also physiologically responsible for the uptake, storage, and disposal of nutrients, drugs and toxins including environmental pollutants. Previous studies have demonstrated that hepatic hepcidin expression is essentially regulated by erythropoiesis demand (Pak et al., 2006) and inflammation (Nemeth et al., 2004). Thus far, no study has been preformed to investigate the potential regulation of hepcidin expression by environmental pollutants. PCBs, as a 
A)

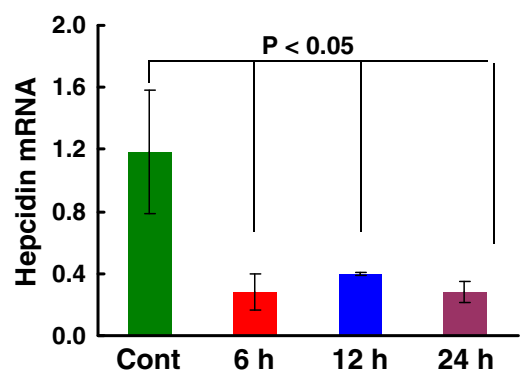

C)

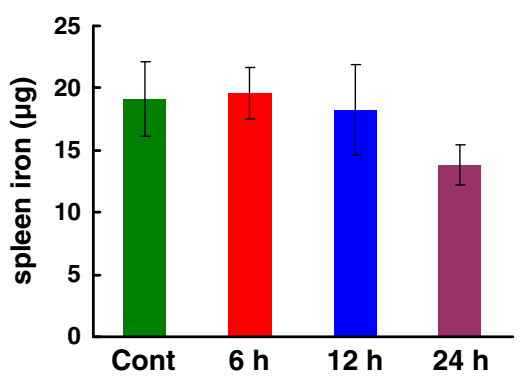

B)

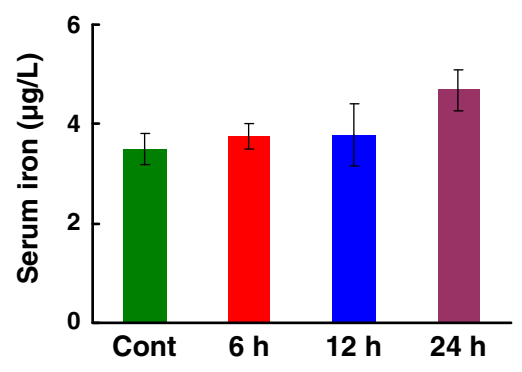

D)

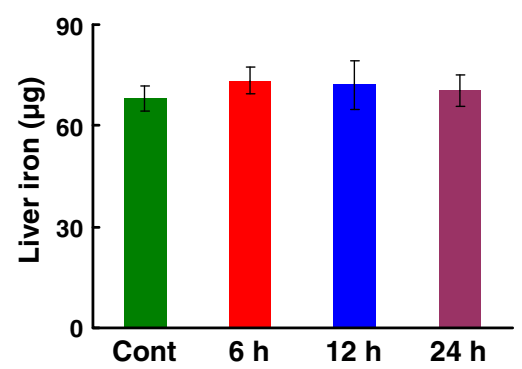

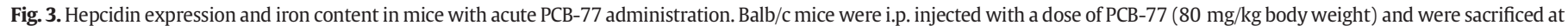
different time points as indicated. Hepatic hepcidin mRNA level (A), serum iron (B), total spleen iron content (C) and total liver iron (D) were then determined $(n=5)$.

class of persistent environmental toxicants, are readily accumulated in liver and fat due to their pronounced feature of lipophilicity (Kodavanti et al., 1998). We here demonstrated that PCB-77 greatly disrupted systemic iron homeostasis by suppressing hepatic hepcidin expression, coupled with increased serum iron and decreased spleen iron. Our group and the other group have found two estrogen response elements (ERE) in the promoter region of hepcidin and described an inhibitory effect of estrogen on hepcidin expression (Hou et al., 2012; Yang et al., 2012). PCBs are endocrine-disrupting chemicals with estrogen-like effects (Kuch et al., 2010), and they could mimic estrogen and disturb the endocrine system and the organs that respond to endocrine signals in organisms (Młynarczuk and Kotwica, 2006). To this end, we would assume that PCBs inhibit hepatic hepcidin expression through the estrogen-like effects, yet this hypothesis needs further detailed investigation.

Disorders in iron homeostasis are associated with a variety of diseases. The major clinical manifestation of iron deficiency is anemia. In iron deficiency, multiple aspects of cellular functions are compromised, leading to cell growth arrest, differentiation blockade, etc (Ghosh, 2006). On the other hand, iron overload could also cause numerous diseases such as liver cirrhosis (Pietrangelo, 2011). Patients of $\beta$ thalassemia (Pennell et al., 2010) and hemochromatosis (Halpern et al., 2009) usually develop severe iron overload due to hepcidin deficiency, and these patients eventually suffer from various disorders
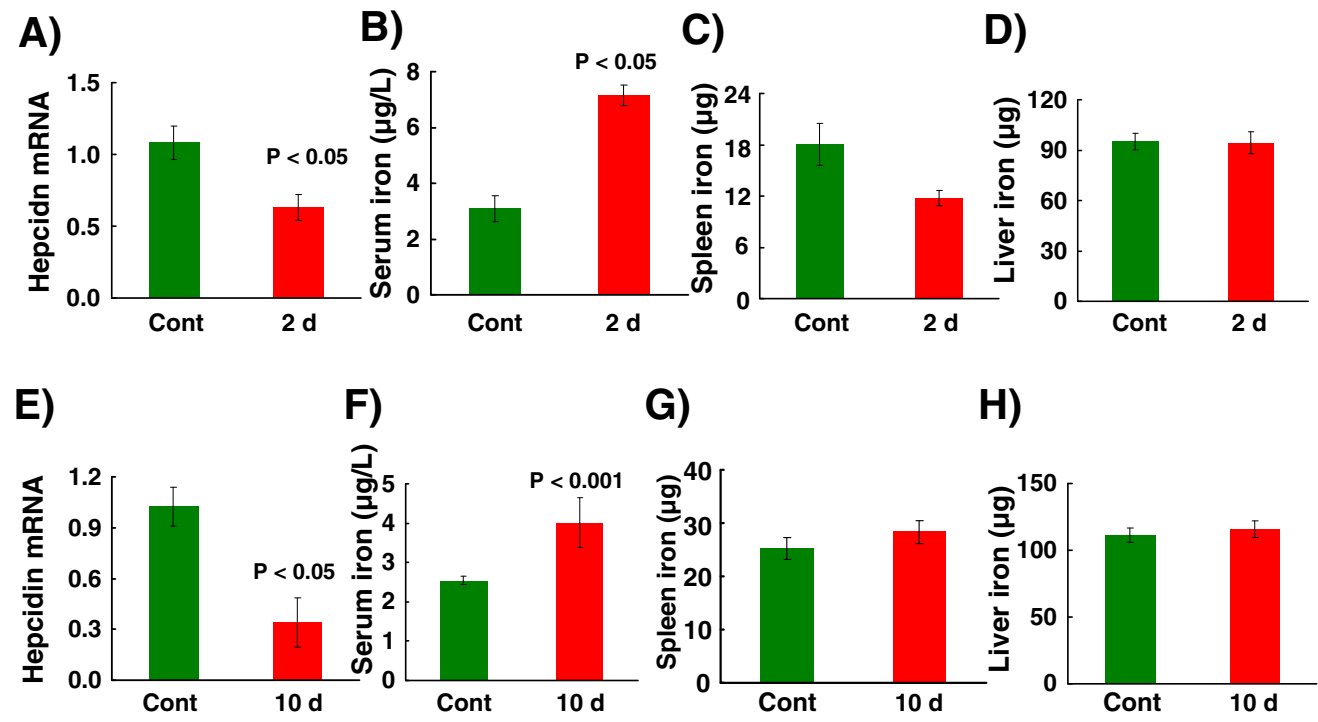

G)

H)
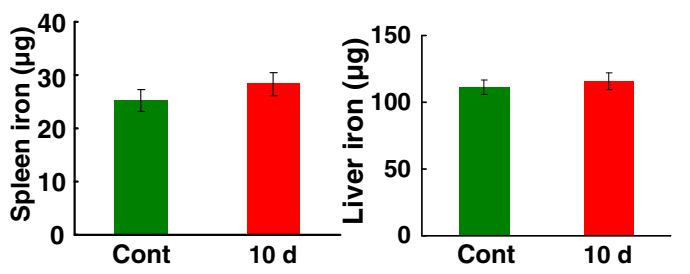

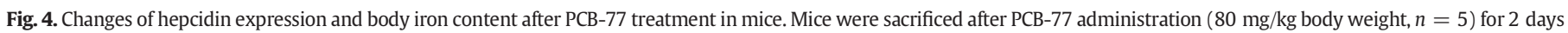
and 10 days, respectively. (A and E) Relative hepcidin mRNA level. (B and F) Serum iron. (C and G) Total spleen iron. (D and H) Total liver iron. 
coupled to excess iron, such as heart failure (Anker et al., 2009). Reduced levels of hepcidin also occur in untreated patients with infection of chronic hepatitis $C$ virus despite ongoing inflammation, leading to predisposition to hepatic iron loading (Drakesmith and Prentice, 2012). Previous studies have shown that high serum levels of PCBs are associated with an increased risk of breast cancer, and PCBs are implicated in promoting breast cancer progression (Aronson et al., 2000). Some epidemiological studies also suggest that PCB accumulation in mammary tissues is linked with high-grade tumors and overall poor prognosis in breast cancer patients (Snedeker, 2001; Woolcott et al., 2001). So far, the mechanisms underlying the correlation between PCB exposure and cancer occurrence and progression are still not understood. Excess iron availability and supply in cells increase the likelihood of gene mutation through production of free radicals and also provide a favorable environment for the growth of tumor cells (Bystrom et al., 2012; Torti and Torti, 2011). A large number of studies have delineated the considerable contribution altered iron metabolism to tumor development (Bystrom et al., 2012; Richardson et al., 2009; Torti and Torti, 2011). For example, case-control surveys of breast cancer patients revealed that intake of meat-derived heme-iron increased the risk of breast cancer (Ferrucci et al., 2009; Kallianpur et al., 2008). Therefore, our current study provides an additional novel mechanism by which PCBs instigate cancer progression through disturbing systemic iron homeostasis.

To summarize, our results demonstrate that PCB-77 significantly suppresses hepatic hepcidin expression in vitro and in vivo at nontoxic concentrations. PCB-77 greatly disturbs systematic iron homeostasis coupled with increased serum iron and decreased spleen iron concentrations in mice.

\section{Authors' contributions}

S.L. and L.W. conceived and designed the study. L.W., S.Z. and L.L. carried out experiments, and analyzed the data. D.Z. and X.L. contributed reagents and materials. L.W. wrote the paper. S.L. revised the article. All authors read and approved the final article.

\section{Conflict of interest}

No potential conflicts of interest were disclosed from the authors. There are no non-financial competing interests (political, personal, religious, ideological, academic, intellectual, commercial or any other) to declare in relation to this manuscript.

\section{Acknowledgments}

This work was supported by grants from the Chinese Academy of Sciences (KZCX2-EW-404), the National Natural Science Foundation of China (grant numbers: 21077128, 20921063, 21177151, 21207152), and the Chinese Academy of Sciences program "Hundreds Talents."

\section{References}

Andriopoulos Jr., B., et al., 2009. BMP6 is a key endogenous regulator of hepcidin expression and iron metabolism. Nat. Genet. 41, 482-487.

Anker, S.D., et al., 2009. Ferric carboxymaltose in patients with heart failure and iron deficiency. N. Engl. J. Med. 361, 2436-2448.

Aronson, K.J., et al., 2000. Breast adipose tissue concentrations of polychlorinated biphenyls and other organochlorines and breast cancer risk. Cancer Epidemiol. Biomark. Prev. 9, 55-63.

Banzet, S., Sanchez, H., Chapot, R., Bigard, X., Vaulont, S., Koulmann, N., 2012. Interleukin-6 contributes to hepcidin mRNA increase in response to exercise. Cytokine 58, $158-161$.

Bekri, S., et al., 2006. Increased adipose tissue expression of hepcidin in severe obesity is independent from diabetes and NASH. Gastroenterology 131, 788-796.

Benarroch, E.E., 2009. Brain iron homeostasis and neurodegenerative disease. Neurology $72,1436-1440$.

Birnbaum, L.S., 1994. Endocrine effects of prenatal exposure to PCBs, dioxins, and other xenobiotics: implications for policy and future research. Environ. Heal. Perspect. $102,676$.
Burgin, D.E., Diliberto, J.J., Derr-Yellin, E.C., Kannan, N., Kodavanti, P., Birnbaum, L.S., 2001. Differential effects of two lots of aroclor 1254 on enzyme induction, thyroid hormones, and oxidative stress. Environ. Heal. Perspect. 109, 1163.

Bystrom, L.M., Guzman, M., Rivella, S., 2012. Iron and ROS: friends or foes of cancer? Antioxid. Redox Signal. 121202124904000

COLE, D.R., PLAPP, F.W., 1974. Inhibition of growth and photosynthesis in Chlorella pyrenoidosa by a polychlorinated biphenyl and several insecticides. Environ. Entomol. 3, 217-220.

Drakesmith, H., Prentice, A.M., 2012. Hepcidin and the iron-infection axis. Science 338 768-772.

Duce, J.A., et al., 2010. Iron-export ferroxidase activity of $\beta$-amyloid precursor protein is inhibited by zinc in Alzheimer's disease. Cell 142, 857-867.

Elizabeta Nemeth, M.S.T., et al., 2004. Hepcidin regulates cellular iron efflux by binding to ferroportin and inducing its internalization. Science 306, 2090-2093.

Evstatiev, R., Gasche, C., 2012. Iron sensing and signalling. Gut 61, 933-952.

Fei, S., Fengqun, Z., Chunji, L., 2006. Clinical meaning of serum ferritin, iron in chronic hepatitic B [J]. J. Xi'an Jiaotong Univ. (Med. Sci.) 3, 024

Ferrucci, L., et al., 2009. Intake of meat, meat mutagens, and iron and the risk of breast cancer in the Prostate, Lung, Colorectal, and Ovarian Cancer Screening Trial. Br. J. Cancer 101, 178-184.

Ganeshaguru, K., Hoffbrand, A.V., Grady, R.W., Cerami, A., 1980. Effect of various iron chelating agents on DNA synthesis in human cells. Biochem. Pharmacol. 29, 1275-1279.

Ganz, T., 2010. The role of hepcidin in iron homeostasis. Iron Deficiency and Overload.Springer 51-64.

Ganz, T., Nemeth, E., 2011. The hepcidin-ferroportin system as a therapeutic target in anemias and iron overload disorders. ASH Education Program Book 2011 $538-542$.

Ghosh, K., 2006. Non haematological effects of iron deficiency - a perspective. Indian J. Med. Sci. 60, 30-37.

Halpern, Z., Rahmani, R., Levo, Y., 2009. Severe hemochromatosis: the predominant clinical manifestation of congenital dyserythropoietic anemia type 2. Acta Haematol. 74, 178-180.

Hawkins, D.H., Abrahamse, H., 2006. The role of laser fluence in cell viability, proliferation, and membrane integrity of wounded human skin fibroblasts following helium-neon laser irradiation. Lasers Surg. Med. 38, 74-83.

Hou, Y., et al., 2012. Estrogen regulates iron homeostasis through governing hepatic hepcidin expression via an estrogen response element. Gene 511, 398-403.

Jeong, S.Y., David, S., 2003. Glycosylphosphatidylinositol-anchored ceruloplasmin is required for iron efflux from cells in the central nervous system. J. Biol. Chem. 278, 27144-27148

Kallianpur, A.R., et al., 2008. Dietary animal-derived iron and fat intake and breast cancer risk in the Shanghai Breast Cancer Study. Breast Cancer Res. Treat. 107, $123-132$.

Knutson, M.D., Walter, P.B., Ames, B.N., Viteri, F.E., 2000. Both iron deficiency and daily iron supplements increase lipid peroxidation in rats. J. Nutr. 130, 621-628.

Kodavanti, P., Tilson, H., 1996. Structure-activity relationships of potentially neurotoxic PCB congeners in the rat. Neurotoxicology 18, 425-441.

Kodavanti, P.R.S., et al., 1998. Congener-specific distribution of polychlorinated biphenyls in brain regions, blood, liver, and fat of adult rats following repeated exposure to Aroclor 1254. Toxicol. Appl. Pharmacol. 153, 199-210.

Kuch, B., Kern, F., Metzger, J.W., von der Trenck, K.T., 2010. Effect-related monitoring estrogen-like substances in groundwater. Environ. Sci. Pollut. Res. 17, 250-260.

Liu, S., et al., 2007. The function of heme-regulated eIF2alpha kinase in murine iron homeostasis and macrophage maturation. J. Clin. Invest. 117, 3296-3305.

Loch-Caruso, R., 2002. Uterine muscle as a potential target of polychlorinated biphenyls during pregnancy. Int. J. Hyg. Environ. Health 205, 121-130.

Lucena, R.A., Allam, M.F., Costabeber, I.H., Villarejo, M.L., Navajas, R.F., 2001. Breast cancer risk factors: PCB congeners. Eur. J. Cancer Prev. 10, 117-119.

Młynarczuk, J., Kotwica, J., 2006. Influence of polychlorinated biphenyls on LH-stimulated secretion of progestereone and oxytocin from bovine luteal cells. Pol. J. Vet. Sci. 9 101.

Nemeth, E., Ganz, T., 2006. Regulation of iron metabolism by hepcidin. Annu. Rev. Nutr. $26,323-342$.

Nemeth, E., et al., 2004. IL-6 mediates hypoferremia of inflammation by inducing the synthesis of the iron regulatory hormone hepcidin. J. Clin. Invest. 113 1271-1276.

Nicolas, G., et al., 2001. Lack of hepcidin gene expression and severe tissue iron overload in upstream stimulatory factor 2 (USF2) knockout mice. Sci. Signal. 98, 8780.

Pak, M., Lopez, M.A., Gabayan, V., Ganz, T., Rivera, S., 2006. Suppression of hepcidin during anemia requires erythropoietic activity. Blood 108, 3730-3735.

Pennell, D.J., et al., 2010. Efficacy of deferasirox in reducing and preventing cardiac iron overload in $\beta$-thalassemia. Blood 115, 2364-2371.

Pietrangelo, A., 2011. Hepcidin in human iron disorders: therapeutic implications. J. Hepatol. 54, 173.

Portigal, C.L., Cowell, S.P., Fedoruk, M.N., Butler, C.M., Rennie, P.S., Nelson, C.C., 2002. Polychlorinated biphenyls interfere with androgen-induced transcriptional activation and hormone binding. Toxicol. Appl. Pharmacol. 179, 185-194.

Richardson, D., Kalinowski, D., Lau, S., Jansson, P., Lovejoy, D., 2009. Cancer cell iron metabolism and the development of potent iron chelators as anti-tumour agents. Biochim. Biophys. Acta Gen. Subj. 1790, 702-717.

Richthoff, J., et al., 2003. Serum levels of 2, 2', 4, 4', 5, 5'-hexachlorobiphenyl (CB-153) in relation to markers of reproductive function in young males from the general Swedish population. Environ. Heal. Perspect. 111, 409.

Safe, S.H., 1994. Polychlorinated biphenyls (PCBs): environmental impact, biochemical and toxic responses, and implications for risk assessment. Crit. Rev. Toxicol. 24, 87-149. 
Schantz, S.L., Widholm, J.J., Rice, D.C., 2003. Effects of PCB exposure on neuropsychological function in children. Environ. Health Perspect. 111, 357-576.

Serrano, J., Puupponen-Pimiä, R., Dauer, A., Aura, A.M., Saura-Calixto, F., 2009. Tannins: current knowledge of food sources, intake, bioavailability and biological effects. Mol. Nutr. Food Res. 53, S310-S329.

Smialowicz, R.J., Andrews, J.E., Riddle, M.M., Rogers, R.R., Luebke, R.W., Copeland, C.B., 1989. Evaluation of the immunotoxicity of low level PCB exposure in the rat. Toxicology $56,197-211$.

Snedeker, S.M., 2001. Pesticides and breast cancer risk: a review of DDT, DDE, and dieldrin. Environ. Heal. Perspect. 109, 35.

Torti, S.V., Torti, F.M., 2011. Ironing out cancer. Cancer Res. 71, 1511-1514.

Tryphonas, H., 1995. Immunotoxicity of PCBs (aroclors) in relation to Great Lakes. Environ. Heal. Perspect. 103, 35.
Wolff, M.S., Zeleniuch-Jacquotte, A., Dubin, N., Toniolo, P., 2000. Risk of breast cancer and organochlorine exposure. Cancer Epidemiol Biomarkers Prev. 9, 271-277.

Woolcott, C.G., et al., 2001. Organochlorines and breast cancer risk by receptor status, tumor size, and grade (Canada). Cancer Causes Control 12, 395-404.

Yang, Q., Jian, J., Katz, S., Abramson, S.B., Huang, X., 2012. 17ß-Estradiol inhibits iron hormone hepcidin through an estrogen responsive element half-site. Endocrinology 153, 3170-3178.

Yoshimura, H., Yoshihara, S.i., Ozawa, N., Miki, M., 1979. Possible correlation between induction modes of hepatic enzymes by PCBs and their toxicity in rats. Ann. N. Y. Acad. Sci. 320, 179-192.

Zheng, T., et al., 2000. Breast cancer risk associated with congeners of polychlorinated biphenyls. Am. J. Epidemiol. 152, 50-58. 